\title{
Effects of provisioning ecotourism activity on the behaviour of white sharks Carcharodon carcharias
}

\author{
R. Karl Laroche ${ }^{1, *}$, Alison A. Kock ${ }^{2,3}$, Lawrence M. Dill ${ }^{1}$, W. Herman Oosthuizen ${ }^{4}$ \\ ${ }^{1}$ Behavioural Ecology Research Group, Department of Biological Sciences, Simon Fraser University, Burnaby, \\ British Columbia V5A 1S6, Canada \\ ${ }^{2}$ Shark Research Centre, Iziko South African Museum, P.O. Box 61, Cape Town 8001, South Africa \\ ${ }^{3}$ Department of Zoology, University of Cape Town, Private Bag, Rondebosch 7701, South Africa \\ ${ }^{4}$ Marine and Coastal Management Branch, Department of Environmental Affairs and Tourism, Private Bag X2, \\ Roggebaai 8012, South Africa
}

\begin{abstract}
Ecotourism operations which provide food to large predators have the potential to negatively affect their target species, by conditioning them to associate humans with food, or by generally altering their behavioural patterns. This latter effect could have potentially detrimental consequences for the ecosystem inhabited by the predator, because any behavioural changes could affect the species with which they interact. We present the results of an experimental study conducted from June to October 2004, which examined the effects of provisioning ecotourism on the behaviour of white sharks around a seal colony on a small island in South Africa. Although ecotourism activity had an effect on the behaviour of some sharks, this was relatively minor, and the majority of sharks showed little interest in the food rewards on offer. It is unlikely that conditioning would occur from the amount of ecotourism activity tested, because even those sharks identified supplying most of the data presented here (which may be more strongly predisposed towards conditioning, as their persistence around the boat is what allowed them to be identified) showed a nearly ubiquitous trend of decreasing response with time. Furthermore, even the sharks frequently acquiring food rewards typically stopped responding after several interactions. Consequently, moderate levels of ecotourism probably have only a minor impact on the behaviour of white sharks, and are therefore unlikely to create behavioural effects at the ecosystem level.
\end{abstract}

KEY WORDS: Provisioning ecotourism $\cdot$ White shark $\cdot$ Behavioural effects $\cdot$ Indirect interactions

\section{INTRODUCTION}

Nature-based tourism, or ecotourism, is increasing rapidly on a worldwide scale (Wearing \& Neill 1999), allowing humans to interact with a multitude of species in different environments. Its benefits range from local economic development to the fostering of conservation-friendly attitudes in the general populace (Miller 1993, Orams 1995, Mangel et al. 1996, Barkin 2003, Kiss 2004, Jones 2005, Krueger 2005). However, ecotourism activity also has the potential to adversely affect a target species by creating a disturbance which significantly alters an animal's behaviour. For example, animals being observed might perceive benign human presence as a predation risk (e.g. Burger \& Gochfeld 1998, Williams et al. 2002, McClung et al. 2004, Nevin \& Gilbert 2005). In this scenario, any risk averse behaviour adopted by the animals would likely result in the reduction of other fitness-accruing activities (i.e. foraging, resting, etc.; Gill \& Sutherland 2000, Frid \& Dill 2002).

Ecotourism operations seek to deliberately alter the behaviour of their target species, using food incentives to bring animals to the tourists (Orams 2002). These operations often 'showcase' elusive predators that would usually ignore or avoid tourists altogether (Orams et al. 1996, Burgess 1998). Still, despite such invasive practices, it is unlikely that this type of provi- 
sioning ecotourism would affect an animal's fitness in the manner described above; tourist food can be obtained at little or no energy cost, and the animals are at liberty to depart if conditions become unfavourable. Tourist presence should thus be perceived not as a negative threat, but rather as a positive feeding opportunity. Nonetheless, provisioning ecotourism could negatively affect a target species, for example by creating a dependency on tourist food, fostering aggression towards humans, or through incidental disease or injury (Orams 2002).

Perhaps most importantly, the predators sought out by these operations are components of an ecosystem, correspondingly interacting with numerous species, including their prey. Consequently, changing the predator's behaviour carries the risk of altering the dynamics of these interactions (Orams 2002). The end result could be a series of behaviourally mediated indirect interactions between the tourists, the predators, and any other species, the positive and negative effects of which could theoretically cascade throughout the ecosystem (Wootton 1993, Abrams et al. 1996, Yodzis 2000, Dill et al. 2003).

Given its apparent potential for inducing behavioural changes, the need to determine the direct impact of provisioning ecotourism on the behaviour of a target species should be evident. To address these questions, we explored the potential impacts of a provisioning ecotourism operation on a large predator: South Africa's white shark Carcharodon carcharias.

Shark ecotours operate at several locations along the South African coastline, all based on specific Cape fur seal Arctocephalus pusillus pusillus colonies (Ferreira \& Ferreira 1996), a preferred prey item of the white shark. The waters surrounding these colonies have large numbers of sharks during the southern hemisphere's winter (May to September) and these actively hunt seals (Martin et al. 2005). Evidence from numerous sites around the world suggests that this involves swimming at depth and inspecting the water above for seal-shaped silhouettes (Klimley 1994, Anderson et al. 1996, Strong 1996, Kock 2002; R. K. Laroche unpubl. data from Seal Island). This strategy allows the sharks to easily spot any seals above them, while remaining unseen. The end result is an ambush attack, limiting the shark's energy expenditure and risk of injury, while maximizing success rate (Martin et al. 2005).

Unfortunately, the basic goals of the ecotourism industry directly conflict this strategy. These are simple: to attract as many sharks as possible to the surface, and to keep them around the tour boat for as long as possible. It would seem that if these goals were attained, sharks would spend far less time hunting, and at the very least forfeit the tactical advantage they gain by remaining low in the water column and not remaining in one clearly defined area. Thus, the potential exists for the white shark tourism industry to not only alter the sharks' behaviour, but for this result to reduce the predatory pressure they exert on the seals: a possible step towards tourism impact cascading throughout the entire ecosystem. The key to determining whether this is occurring is to first establish whether white shark ecotourism boats are altering the behaviour of their target species.

\section{MATERIALS AND METHODS}

Study site. The research was conducted around Seal Island, a small island located in False Bay, in the Western Cape region of South Africa (Fig. 1). The island has a year-round population of between 36000 and 77000 Cape fur seals (South African Marine and Coastal Management unpubl. data), and is the only seal breeding colony within the bay (Butterworth et al. 1987, Shaughnessy 1987). The waters surrounding the island also support large numbers of white sharks from May through September. The South African government issues permits to 3 white shark ecotourism operators every year for this period, allowing these individuals to approach and closely view natural predatory events, as well as to attract sharks to their boats for tourists to watch.

The typical ecotour excursion to Seal Island involves arriving at the island shortly before sunrise and drifting for 2 to $3 \mathrm{~h}$, moving freely to predation events as and when they occur. A seal-shaped decoy is then usually towed around the island (an activity designed to elicit shark predatory breaches) for approximately $30 \mathrm{~min}$, and finally the boats anchor and disperse organic attractant (chum: typically mashed sardine and fish oil, although occasionally including minced tuna or shark liver; bait: fish chunks or shark heads) in the water with the hopes of luring nearby sharks to the boat. Chumming will often continue into the early afternoon, after which operators return to port. This standard of ecotourism activity is adhered to on the majority of excursions, and was developed to exploit the fact that most shark predatory behaviour at the island is observed during the hours around sunrise (Martin et al. 2005). Still, operators do deviate from the model occasionally, for example by chumming or towing the entire day.

Acoustic equipment. At various times during the field season (May to October 2004), 17 white sharks were tagged with Vemco Rcode acoustic transmitters, of which 7 were model V16, and the remainder V16P (added pressure sensitivity for swimming depth measurement). In all cases, sharks were enticed to our boat by means of various forms of attractant (fish oil, 


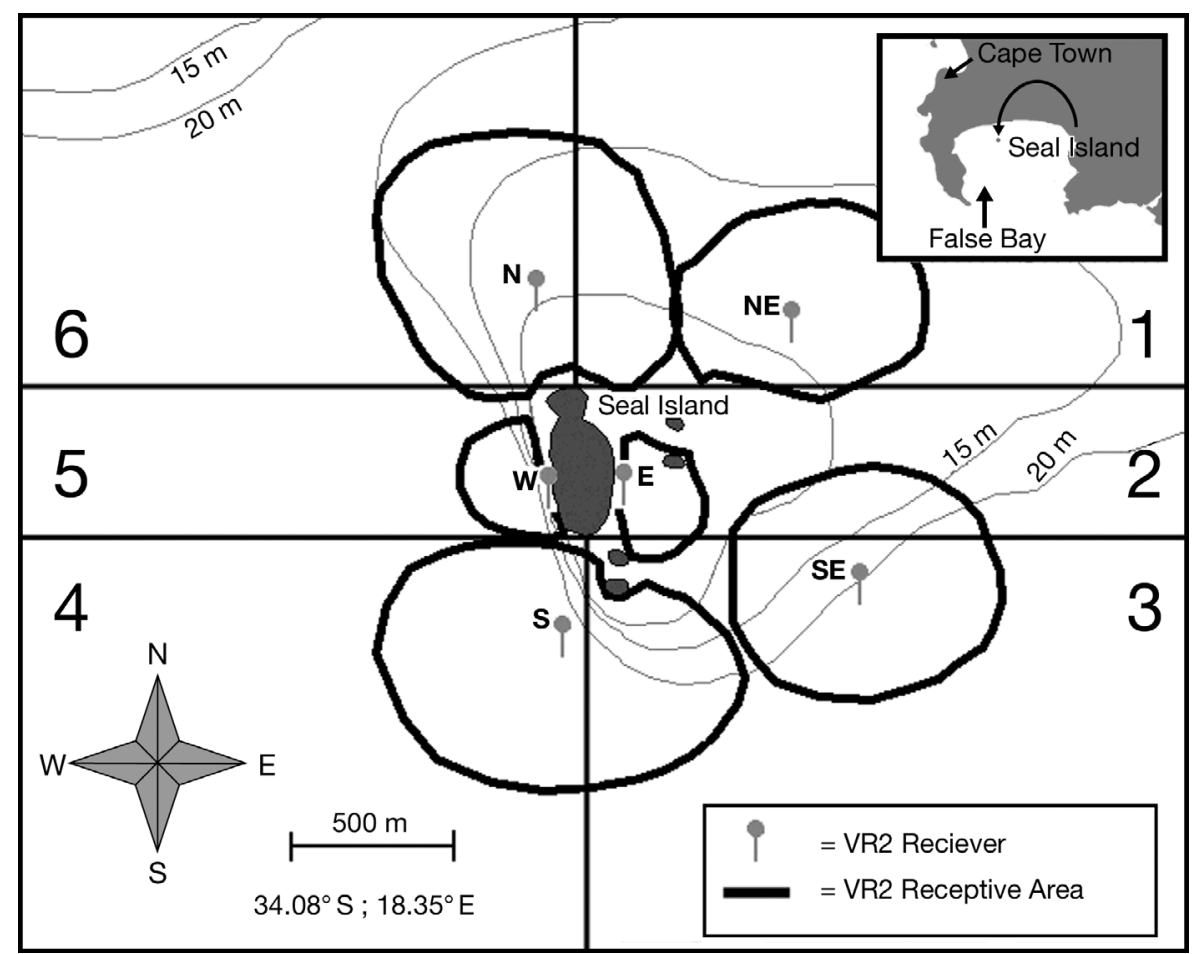

Fig. 1. Seal Island, False Bay, South Africa. Locations of the 6 VR2 receivers, and the average receptive area of each. Waters around the island were divided into 6 sectors (1-6 on map), from which the location of a given research activity was randomly selected

sardine, shark liver, whale blubber; also a seal-shaped decoy cut from carpet), and coaxed to stay with large chunks of fish bait. Sharks were lured close to the boat, at which point a tag was attached subcutaneously by means of a small plastic barb and a metal spear.

Data were collected from the acoustic transmitters using 6 Vemco model VR2 data logging receivers. These were deployed along the ocean floor at various locations around Seal Island (Fig. 1), anchored to the bottom by means of a truck tire filled with concrete.

Experimental activity. Chumming experiments were conducted from June to October 2004, during which time we traveled to Seal Island whenever possible, for an average of $15 \mathrm{~d} \mathrm{mo}^{-1}$. When present at the island, our time was split between 2 distinct activities: (1) dedicated watching for predatory activity and seal movement, which meant that the boat was adrift and no attractant was placed in the water; and (2) chumming for sharks, where the boat was anchored and attractant was deployed.

Waters surrounding Seal Island were divided into 6 sectors (Fig. 1), and time of day divided into four $2.5 \mathrm{~h}$ blocks between 07:30 and 17:30 h (occasionally additional time was extended beyond this period). Our choice of either activity at the island was then randomly selected and assigned to a specific sector for each time block, using Microsoft Excel's random num- ber function. In total, we were present for, and collected data during, 169 time blocks.

Visual records. Visual records were kept of observed shark activity around our boat. Individual sharks were described using unique scarring or pigmentation patterns, to facilitate identification. Unfortunately, markings on most sharks were not distinct enough to allow for clear recognition over multiple days. However, some sharks were easily distinguishable, and were thus recorded as 'identified sharks' if re-sighted on any subsequent days. All tagged sharks were individually identified.

Shark presence at the boat was recorded on a minute by minute basis. The total number of minutes during which a shark was recorded at our boat on a single day was defined as its 'contact time'. This measure was weighted by the total potential contact time during a day (i.e. the total number of minutes during which attractant was in the water), providing a 'proportional contact time' with which to measure shark response to chum.

Analysis. The general hypothesis underpinning this study was that sharks would respond favourably to the presence of chum. The expectation was therefore that sharks would spend more time within the vicinity of the boat (and the nearest VR2 receiver) when chum was in the water, and correspondingly less time around other 
areas of the island (i.e. the other 5 receivers). This expectation was tested by contrasting the differences in receiver records between experimental chumming and control non-chumming conditions for the receivers closest to the chum source (anchoring location around the island was randomly assigned), as well as those that were successively further away. By contrasting data separately for each receiver, it was possible to control for any potential confounding effects of non-random shark movement around Seal Island.

However, despite implementation of the experimental protocols described above, the realized 'chumming' environment often departed from ideal experimental conditions. The presence of ecotourism boats sometimes meant that there were several sources of attractant available at the same time, occasionally on opposite sides of the island. Furthermore, the basic pattern of ecotourist activity was very predictable, which meant that the application of experimental treatments (chumming bouts) was not randomized.

Consequently, data recorded during ecotourist chumming could not be reconciled with the requirements of rigorous statistical analysis, making it necessary to exclude them from the final results. This dramatically decreased the overall data set, and imposed several constraints on the analysis. Most importantly, we were forced to make the assumption that sharks would only respond to chum, and not to the presence of the boats themselves. This was mandated because the reduced data set was not large enough to provide for 2 separate control states differing only in the presence or absence of boats. Instead, those data recorded with and without boats were combined into one unified 'no chum' control, making the assumption of no boat effect necessary.

The non-regimented nature of ecotourist presence also forced us to analyze the data within a different time frame than the one established through experimental protocols. Although our activity at Seal Island was based around four $2.5 \mathrm{~h}$ blocks, these delineations proved unworkable during the analysis because too many data were lost to ecotourist activity (e.g. ecotourist chumming from 12:00 to 13:00 h would have invalidated all the data from 10:00 to 15:00 h). Thus, data were broken up into $1 \mathrm{~h}$ collection periods, usually making it possible to salvage data recorded before, and occasionally even after, ecotourism activity.

Two facets of shark behaviour were explored separately within the VR2 receiver data: shark presence, and shark swimming depth. Both were examined by delineating within the data a set of paired 'chumming' and 'control' (or non-chumming) $1 \mathrm{~h}$ periods. A pair of these periods thus consisted of the data collected by each receiver during $1 \mathrm{~h}$ of chumming, and the data collected by each receiver for the same sharks, during the same hour, on a separate day when no chumming was taking place. Periods were selected to be as similar as possible with regard to individual shark presence and acoustic conditions, using the following criteria: (1) Paired periods could be no more than $2 \mathrm{~d}$ apart. (2) Wind strength could differ by no more than $10 \mathrm{~km} \mathrm{~h}^{-1}$. (3) Swell height could differ by no more than $1 \mathrm{~m}$.

The first hour-long experimental chumming period for a particular day (and its corresponding control) was only defined $1 \mathrm{~h}$ after chumming actually began, thus allowing for chum dispersal time. Successive hour-long periods were then identified up until the point where chumming ceased, or until a disruptive event occurred, such as the initiation of ecotourist chumming. In total, 54 separate $1 \mathrm{~h}$-long pairs of experimental and control periods (total $=108 \mathrm{~h}$ ) were isolated over 20 different paired days (total $=40 \mathrm{~d}$ ). The hour preceding experimental chumming, along with the one situated $1 \mathrm{~h}$ after the cessation of chumming (to allow for any chum effects to abate), were also considered whenever possible, and were defined as 'pre-chumming' and 'post-chumming' periods, respectively.

Before conducting any analyses, all records of shark presence were first weighted by their respective receiver's average receptive area. This was measured by suspending a transmitter $2 \mathrm{~m}$ below the boat and logging time and GPS coordinates during controlled drifts towards or away from a receiver. Each drift was done 3 times for every receiver, in different sea states. Time and GPS records from each drift were then contrasted against receiver data to isolate the time and location of the first or last recorded identification of the suspended Rcode transmitter, and an average distance was calculated for each 3-drift set to estimate receptive boundary points ( 4 for each receiver). Finally, these boundaries were connected and average receptive areas estimated using Arcview 3.2.

All records of shark presence were also weighted by the shortest distance from their receiver to the chum source (to control for varying anchoring locations; the mean distance from the source to the closest receiver was $153 \mathrm{~m}$, to the furthest $964 \mathrm{~m}$ ). Data were then summed for each receiver during each hour-long period, and these values divided by the total records collected from all 6 receivers within the time period. The result of this calculation was a transformation of the data for each receiver into a proportion of total records for that period, correcting for any differences in overall shark abundance between pairs of periods. These proportional values were used to calculate the mean proportional presence per hour-long period per day for each receiver. In so doing, the unit of measurement was shifted from a $1 \mathrm{~h}$ period to a day, a 
step which was required to address the obvious nonindependence of successive hours measured over $1 \mathrm{~d}$.

Paired experimental and control days were contrasted as the difference between the mean proportional presence/period/day for each receiver during both conditions (exp. and con.). These results were then grouped to reflect receiver distance from the chum source on each experimental day, i.e. the receiver nearest to our chumming position on any given day was considered together with the closest receivers from other days, regardless of where around Seal Island we set anchor, and similarly for successively further receivers. Mean differences were found for each receiver distance group, and $t$-tests used to ascertain whether mean differences between chumming and control conditions varied with distance from a chum source, as well as to determine whether any of the means were statistically distinguishable from zero. Analysis of shark depth was conducted using the same methodology, but by substituting a measure of mean swimming depth/period/day for each receiver in the place of proportional shark presence.

The same analysis was also conducted by first calculating the difference in proportional shark presence data during experimental and control hour-long periods for each separate shark at each receiver. However, for this analysis, periods were defined on an individual basis for each shark, to prevent artificial constructs from influencing the results. For each shark, the first hour-long period started at the point when the shark was first recorded after chumming commenced (or the corresponding time on control days), and the last period was defined as the last full hour before the end of experimental conditions. Data were transformed into proportions by weighting the records for each shark at a particular receiver during a time period by the total records for that shark collected from all receivers within the same period. These measures were used to examine the records with regard to each individual shark's reactions to chumming conditions over time. However, this further limited the data set, because only sharks which were recorded during both experimental and control conditions within each paired data set could be utilized.

The first analysis undertaken was an examination of effect differences over the course of successive hours in one day. To this end, all $1 \mathrm{~h}$ periods during which sharks were recorded were considered separately. Means were calculated for each receiver using the first hour exp.-con. differences of each individual shark on a given day (mean first hour difference in proportional presence/receiver/day), and $t$-tests employed to test the same statistical hypotheses as above. The subsequent hour-long period was also analyzed in the same fashion to provide a comparison between succes- sive hours, but there were insufficient data to test the hypotheses beyond the second hour.

Individual shark differences were also used to test chum effects over repeated days of exposure. For this, only records taken from the receivers nearest to the chum source were considered, and periods were again defined on an individual basis. A measure of mean difference in proportional presence/period/day was calculated for each shark, on each successive day it was recorded. A 2-way ANCOVA was then employed to test for independence of individual data points, by determining whether a statistically significant interaction existed between sighting number and the measure of shark presence for each individual shark. A simple linear regression was used on a scatter-plot of the data to describe any prevailing patterns.

Visual records were also used to analyze shark contact times. A 2-sample Kolmogorov-Smirnov test was employed to test the hypothesis of no difference between the distribution of proportional contact times of tagged and untagged sharks. Visual records over repeated encounters were also analyzed in the same manner as the receiver records, presenting the regression of a scatter-plot of proportional contact times as a function of the number of times a shark had been sighted. A 2-way ANCOVA was also employed to test for statistical independence of these data.

\section{RESULTS}

\section{Shark presence}

No statistical differences between the mean proportions of shark presence at successively more distant receivers from the chum source were observed in the records collected during the hours immediately preceding chumming (Fig. 2a; $\mathrm{n}=19$ ), nor during postchumming (Fig. 2c; $\mathrm{n}=9$ ). However, a slight significant difference between receiver distances was apparent when contrasting experimental and control conditions, driven by a mean positive difference for the receiver nearest to the chum source (greater shark presence while chumming: Fig. $2 b ; n=20, p=0.039$ ). This would be the expected result if chum were influencing shark spatial behaviour, but the associated error bars suggest that any possible effects of chum may not be great.

This result is supported by visual records. The distribution of contact times for all sharks observed at our boat indicates that the vast majority of sharks only passed by briefly (Fig. 3a), and demonstrated very little response to the food incentive we were offering. Tagged individuals (which supplied the data for Fig. 2) did demonstrate a greater inclination towards remaining within sight of the boat than untagged sharks 


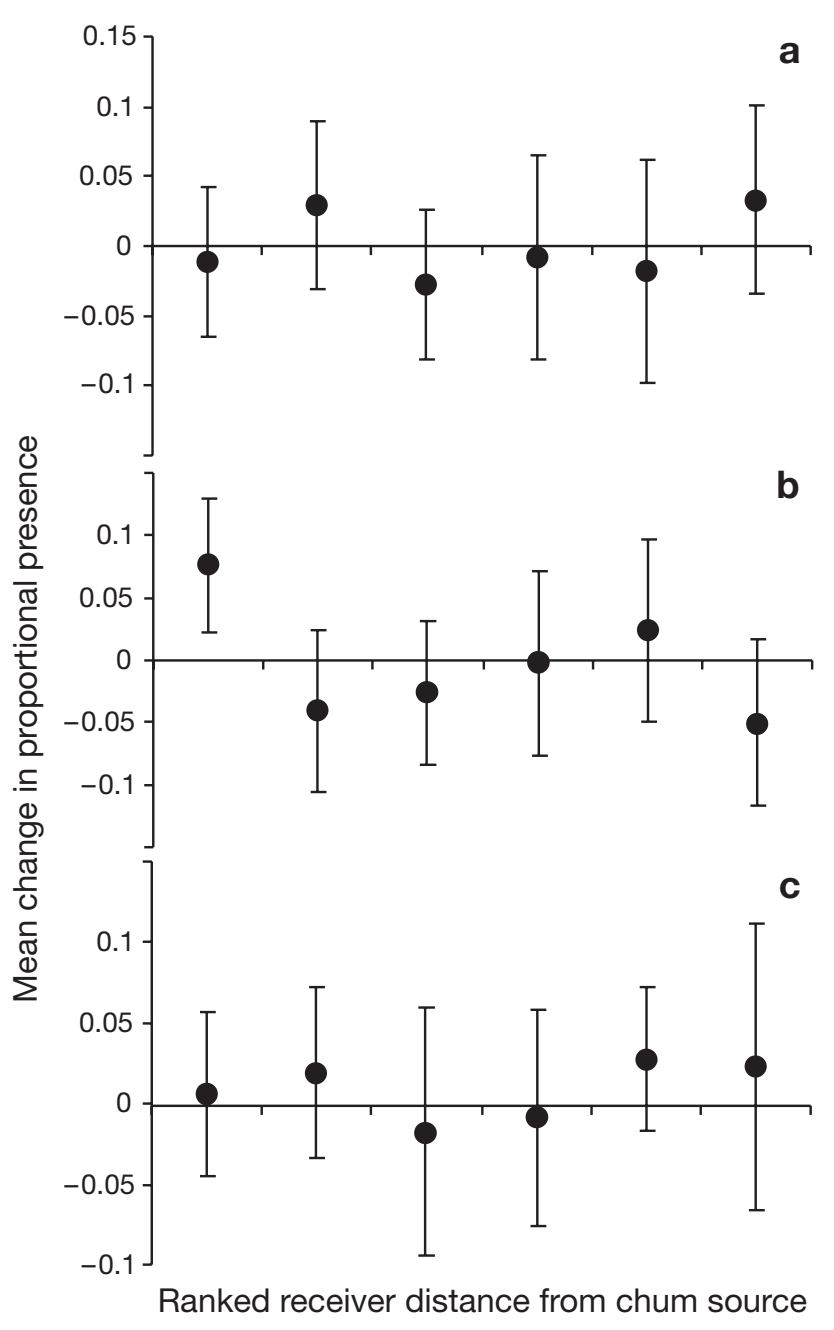

Fig. 2. Effect differences in proportional shark presence between experimental (chum) and control (no chum) conditions for the (a) pre-, (b) experimental, (c) post-chumming hours. For details of calculations see text. Receivers were categorized and grouped based on proximity to the source of attractant (represented on the $x$-axes; closest at the origin). $y$-axes in (a) and (c) represent the mean exp.-con. difference in proportional shark presence for the pre- or post-chumming periods, respectively; $y$-axis in (b) displays the mean exp.-con. difference in average proportional presence/hour/day. Error bars are $95 \%$ CI. Attractant was not dispensed during either pre- or post-chumming periods, and the expected result of no difference between experimental and control conditions was observed. However, an effect of chum on shark movement was detected, indicated by a positive mean difference closer to the chum source, although error bars suggest that this effect is likely not substantial

(Fig. 3b,c; Kolmogorov-Smirnov test, $Z=3.884, \mathrm{p}<$ 0.001), but even these sharks most frequently responded by making a quick pass by the boat.

These results were obtained by summing the data (either receiver or visual records) for all sharks. However, when the same analyses were conducted by first measuring differences in proportional presence for

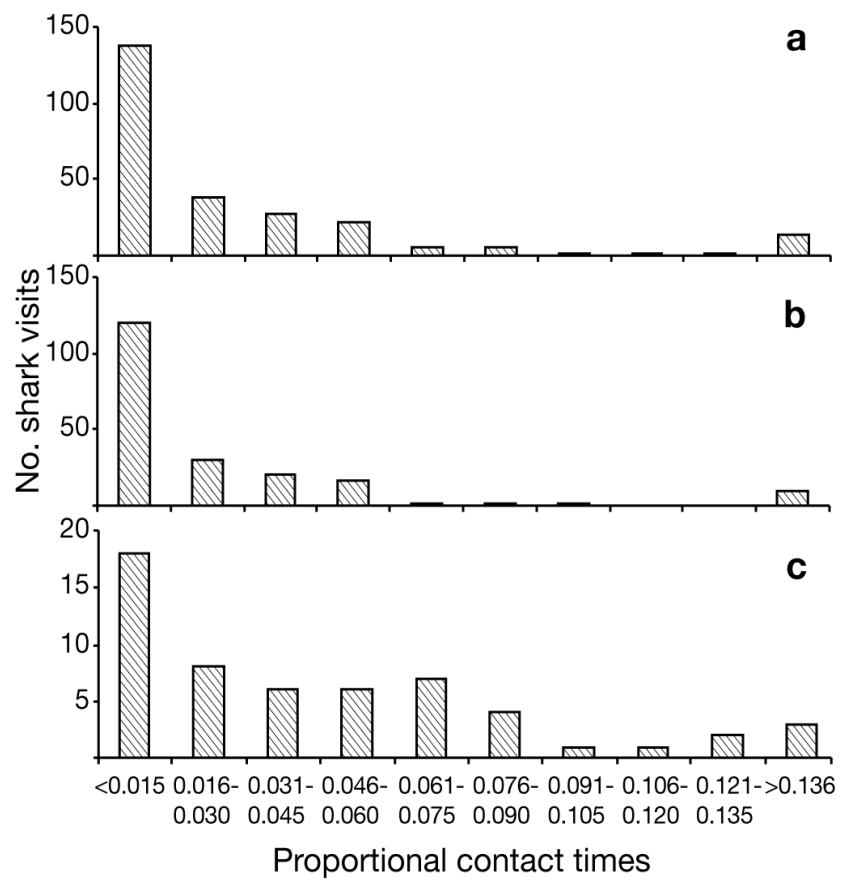

Fig. 3. Distribution of contact times of sharks observed at the boat, weighted by the total amount of time spent chumming on a given day, to give a measure of proportional contact time. Distinction was made between (a) all sharks sighted, (b) untagged sharks, and (c) only those sharks tagged with acoustic transmitters. The vast majority of sightings were very brief, although identified sharks, particularly tagged ones, did spend a higher proportion of time within visual range of the boat

individual sharks, a more distinct result emerged. During the first experimental hour that a shark was recorded, chum appeared to have a significant effect on its behaviour (Fig. 4a; $\mathrm{n}=20, \mathrm{p}=0.0016$ ). However, this effect was greatly diminished during the second hour (Fig. $4 \mathrm{~b} ; \mathrm{n}=13$ ), although a small sample size and large variances render this result suspect.

The data were further explored to gauge the response of individual sharks to chum over repeated days of exposure. Unfortunately, this placed further constraints on the data set, because only 9 sharks appeared in the period records on more than 1 day, and of these only 5 appeared on more than 2 days. Nonetheless, a scatter-plot of the mean paired differences per day for each shark (only for the receivers closest to the chum source) suggests a declining trend in shark response with repeated exposure (Fig. 5). This trend was not statistically significant ( $p=0.1720)$, but is supported by the establishment of a clear empty domain in the upper right portion of Fig. 5. A test of independence did not demonstrate a significant interaction between the number of days recorded and the weighted signal measure of each individual shark (2-way ANCOVA interaction term $\mathrm{p}=0.4864$ ), providing confidence in the observed result. 


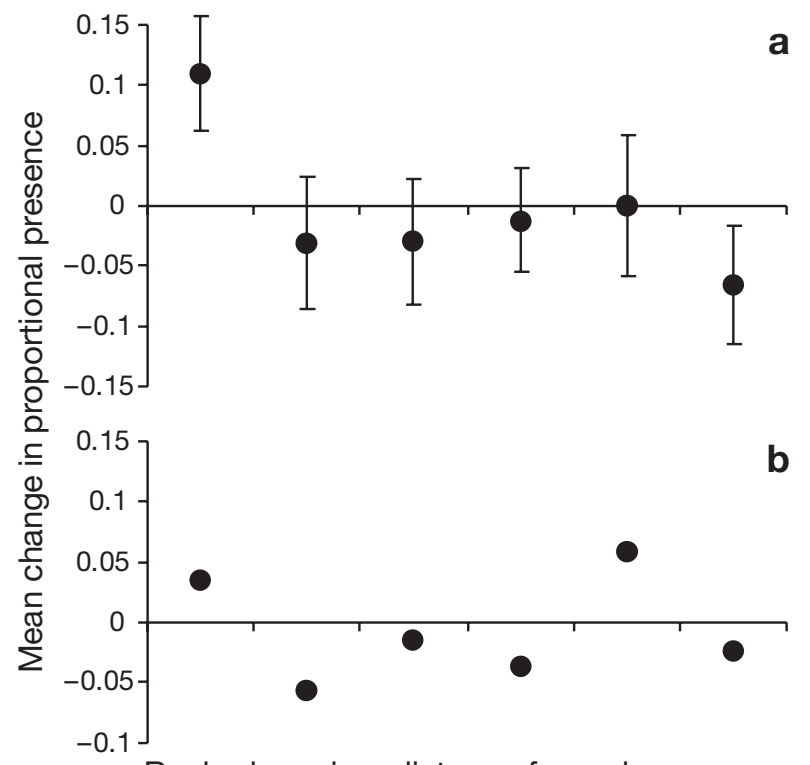

Ranked receiver distance from chum source

Fig. 4. Mean effect differences over single chumming bouts. Results were calculated by first contrasting paired experimental and control hour-long periods for each shark, rather than by combining data for all sharks as in Fig. 2. These individual differences were then categorized and grouped as in Fig. 2. Error bars are $95 \%$ CI. The (a) first and (b) second hours during which a shark was recorded were considered separately from any subsequent hours, from which there were insufficient data to test the hypotheses (see text). The effect of chum on shark movement was more clearly defined and statistically significant during the first hour. This effect was greatly diminished during the second hour, although a small sample size and large variances created substantial errors for these data, preventing the inclusion of confidence intervals in (b)

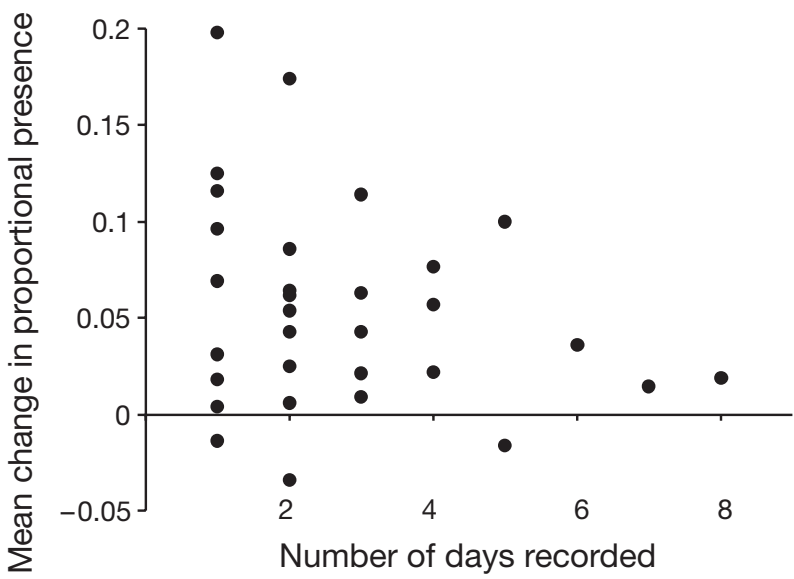

Fig. 5. Mean effect differences for individual sharks measured over each successive day the shark was recorded. $y$-axis represents the difference in proportional shark presence per hourlong period recorded for each individual shark at the receiver nearest to the chum source; $x$-axis represents the days a particular individual was recorded. A non-statistically-significant decreasing trend was observed in shark response with repeated exposure (supported by the empty domain in the upper right portion of the graph), although few sharks appeared in paired records more than 3 times
Once again visual records support the receiver data. A regression run through a similar scatter plot of proportional contact times for all successive sightings of identified sharks demonstrates the same decreasing trend in response, this time with statistical significance (Fig. 6a; 16 re-sighted sharks, p = 0.0029). Unfortunately, very few sharks were sighted more than 5 times, raising the possibility that this pattern was driven by the behaviour of only 1 or 2 sharks. However, a plot of the data gathered from the 7 sharks that were sighted at least 5 times reveals the same significant trend (Fig. 6b, p = 0.0023), lending credence to the previous outcome. Unfortunately, a test of independence revealed a significant interaction between the number of days a shark was sighted and proportional contact time for all 16 sharks, suggesting non-independence of the data (2-way ANCOVA interaction term $\mathrm{p}=0.0171$ ). However, a closer inspection of these data reveals that this interaction is primarily driven by the behaviour of one shark, who displayed the proposed pattern substantially more than the other sharks (Shark 31; Fig. 7). When this shark is removed from consideration, the interaction is no longer significant (2-way ANCOVA interaction term $\mathrm{p}=0.1649$ ). Proportional contact time plots for all sharks are presented in Fig. 7.

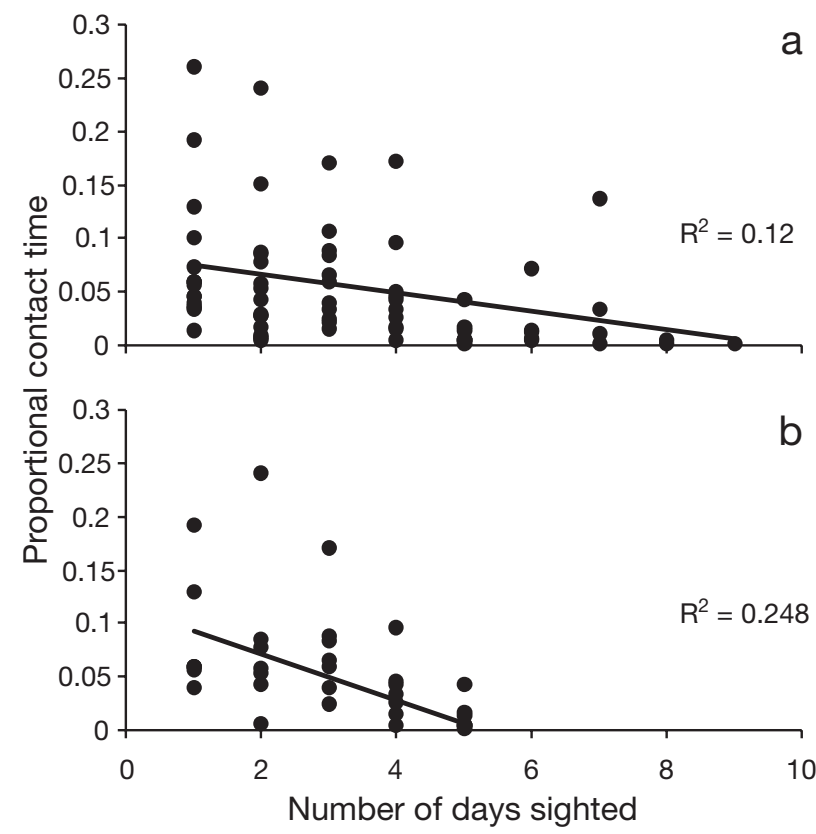

Fig. 6. Proportional contact times (as in Fig. 3) as a function of the number of times a shark was re-sighted for (a) all 16 resighted individuals, and (b) for the 7 sharks which were sighted at least 5 times. Both plots reflect a decreasing trend in shark presence at the boat with repeated sightings, but a test of independence revealed non-independence for the data plotted in (a). However, this likely resulted from the exceptionally dramatic decrease in response of a single shark, and is not considered to be biologically significant. The plots of response over time for each individual shark are included in Fig. 7 


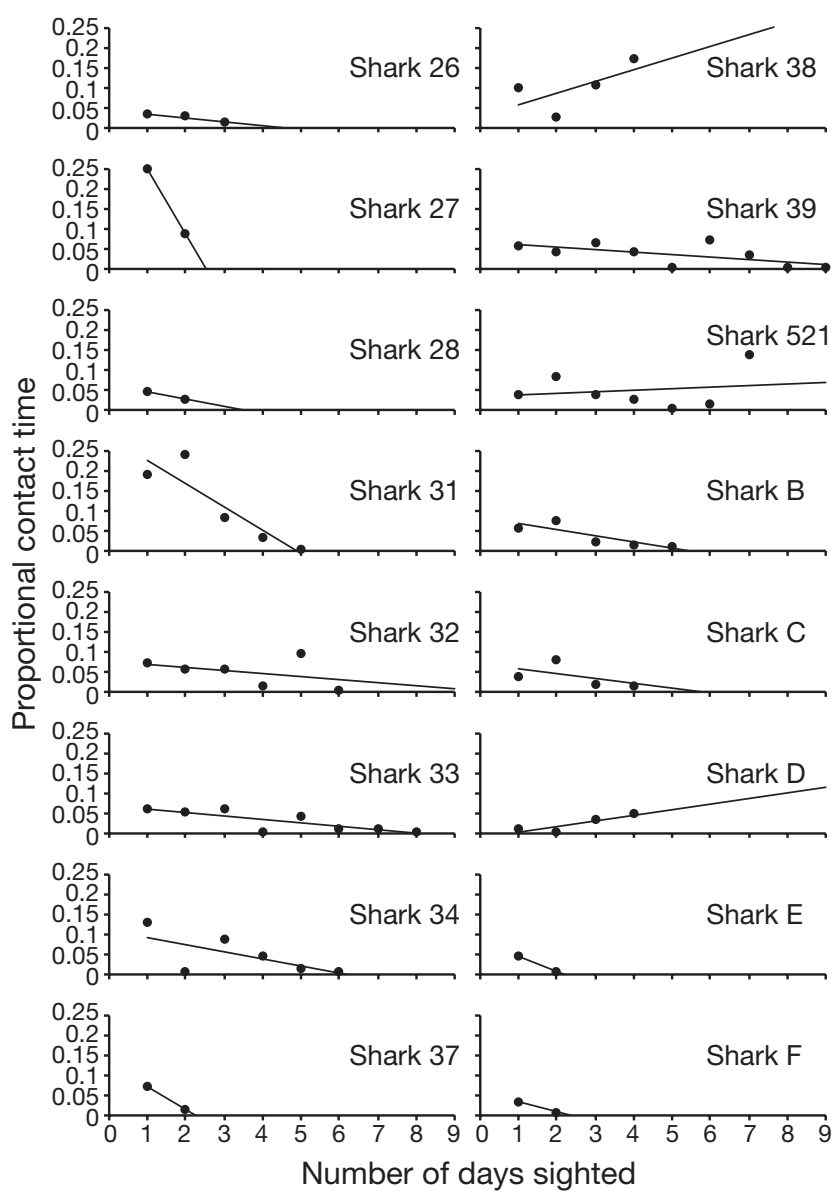

Fig. 7. Plots of proportional contact times against number of days sighted for all 16 re-sighted identified sharks. Only Sharks 38 and D demonstrated a positive response to chum, while the increase in slope for Shark 521 is mitigated by a single point. A 2-way ANCOVA test of independence resulted in a statistically significant interaction term between contact time and sighting number for all 16 sharks $(p=0.0171)$. However, Shark 31 demonstrated an extremely sharp decrease in response. When this shark was removed from the analysis, a test of independence suggested no statistically significant interaction between the terms $(p=0.1649)$

Although the receiver and visual records display similar results, a contrast of the two further supports the theory that shark response to chum is limited and decreases with time. Overall, sharks were only observed at our boat while we were chumming on $36 \%$ of the occasions that they were concurrently recorded around Seal Island, and the majority of these appearances occurred early in the season. This pattern was illustrated by 3 frequently observed sharks (Sharks 32, 39 and 521; Fig. 8), which obtained more rewards than any others (no other shark obtained more than 1 bait). Despite this, all 3 responded to the attractant only occasionally, and Sharks 32 and 39 clearly stopped responding completely with time.

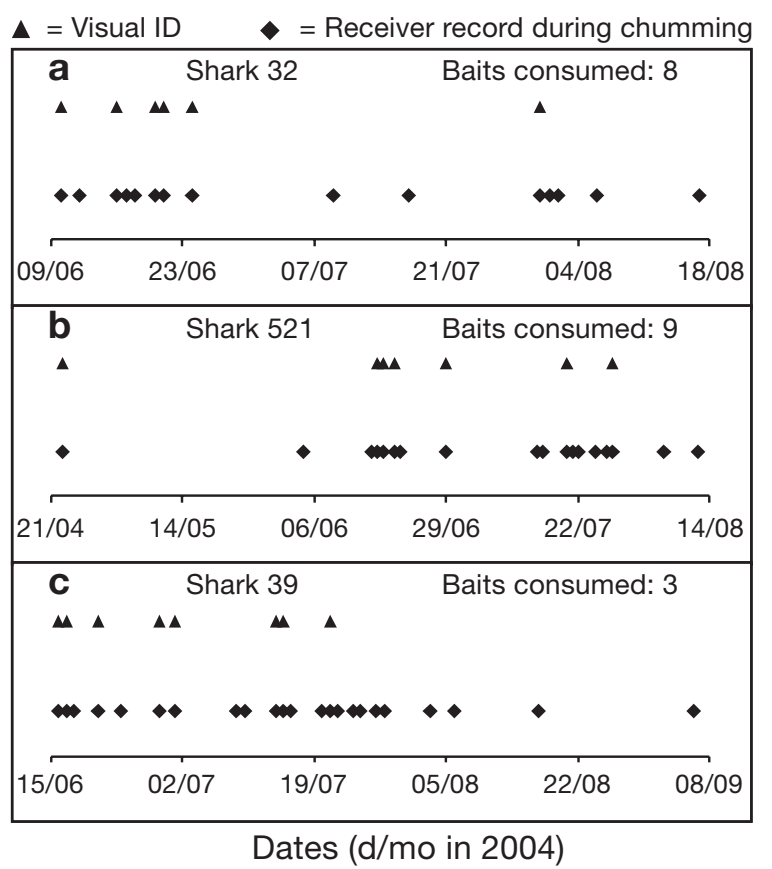

Fig. 8. Number of days that Sharks (a) 32, (b) 521 and (c) 39 were recorded visually during chumming conditions, and the number of days that they were recorded by the VR2 receivers while we were chumming. These data include periods where ecotourism boats were also chumming, but information from observers on these boats suggests that ecotourism response would be similar to that presented here. The last visual observation of Shark 32 was extremely brief and uncertain, as the shark swam past the boat at approximately $8 \mathrm{~m}$ depth. Identification thus needed to be confirmed with receiver records

\section{Shark swimming depth}

Chumming appeared to have a slightly more obvious impact on shark swimming depth. A significant difference in change of swimming depth was observed between the receiver nearest to the chum source and the remaining 5 (Fig. 9; $\mathrm{n}=20, \mathrm{p}=0.023$ ), stemming from a positive difference in swimming depth (deeper depths during control than during chumming) nearest to the chum source and the boat, while none of the other mean differences were statistically distinguishable from zero. This result likely reflects that sharks venture up to the surface to investigate the chum source, while they maintain their normal swimming depth patterns around the remainder of the island.

\section{DISCUSSION}

Despite offering numerous positive benefits, naturebased tourism also has several potential pitfalls, the gravest of which is the possibility of altering the behaviour of the target species. This problem is of particular 


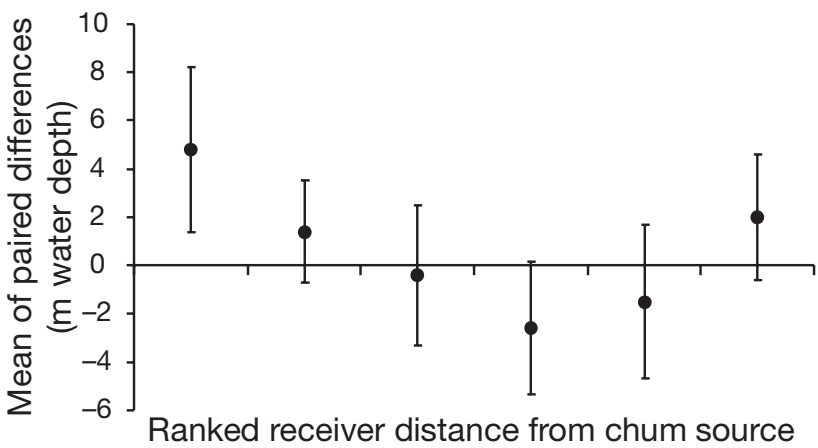

Fig. 9. Means of the differences between paired experimental and control days for shark swimming depth. Results were calculated in the same way as for Fig. 2, except to substitute recorded values of shark swimming depth in the place of measures of proportional shark presence. $x$-axis therefore displays the same categories as Fig. 2 , and the $y$-axis represents the difference in depth $(\mathrm{m})$. Error bars are $95 \%$ confidence intervals. Sharks nearest to the chum source demonstrated a significant positive change in swimming depth (their average swimming depth was more shallow), while sharks recorded around the remainder of the island showed no change

importance when considering ecotourism operations that provide food to the animals, because their success guarantees at least some deviation from natural behaviour in the absence of human activity. The present study sought to examine the effect of such provisioning practices by the South African white shark ecotourism industry on the behaviour of their target species.

\section{Direct impact on sharks}

Sharks are probably present at Seal Island for the sole purpose of hunting seals. Consequently, if chumming had a direct impact on the sharks, this would likely be most evident through a change in some element of their feeding behaviour. Data collected over the field season suggest that predation rate remained relatively consistent throughout the study period (A. A. Kock unpubl. data) and that no decrease occurred during chumming periods, although the non-systematic methodology used to collect these data renders the result highly suspect, and prevented its inclusion in this paper. Nonetheless, an unaffected predation rate does not necessarily preclude the possibility of direct impacts on the sharks' feeding activities.

For one, ecotourists could be conditioning sharks to associate tour boats with food rewards. Such effects could theoretically occur without a drop in predation rate, assuming the sharks never substituted ecotourism fare for live kills, but rather only supplemented their intake. Alternatively, the effects of conditioning in this system might only be manifested over a period longer than the course of this study. However, even in this event, the expectation would be that the overall behavioural patterns prevalent in the data would point towards the potential for conditioning to occur.

This clearly did not appear to be the case. The expected result from a conditioning effect would be an escalation in response or contact time with increased exposure, one which would be especially prevalent in those animals that consistently received more reward. Instead, we observed a nearly ubiquitous trend of decreasing response with time, and those animals that obtained more rewards showed no greater inclination for remaining near the boat (Fig. 8). It should be noted that the contrasts of visual and receiver records do not necessarily rule out the possibility that sharks were present at other tour boats on days when not observed at ours. However, several identified sharks (including those depicted in Fig. 8) could be recognized easily enough to confirm their presence/absence with observers on the tour boats (N. Hammerschlag pers. comm.).

These results emerged despite the fact that our data may represent a sample of sharks that actually have a greater predisposition towards conditioning. Over the course of the field season, it became clear that certain sharks consistently behaved differently to others, for example by displaying decreased wariness around boats or increased aggression towards the bait. These sharks generally displayed a greater affinity for ecotourism offerings, and were more likely to obtain reward. They also were the ones that placed themselves in situations which allowed them to be identified or tagged. Consequently, our results likely overestimate the potential for chumming to lead to conditioning in white sharks.

Unfortunately, conditioning is not the only way that chumming can directly affect the sharks. Extra provisioning could potentially alter residency times at the island, in either a positive or negative direction. It could also theoretically affect shark population structure around the island, if dominant and subordinate individuals react to the chum in different ways. However, despite the fact that it would seem reasonable to surmise that the patterns observed in our data would not translate into changes in shark residency times at the island, nor could the impacts of sparse provisioning have substantial effects on population structure, the short-term nature of the present study makes it impossible to draw any inferences regarding these topics.

\section{Indirect effects on other species}

The species most closely associated with white sharks at Seal Island are their specific prey in this area, the Cape fur seals. Consequently, any changes in shark behaviour elicited by ecotourism would likely have the greatest impact on the seals. However, 
behavioural data recorded for these animals during this study suggested no change in seal activity as a result of ecotourism presence (R. K. Laroche et al. unpubl.), despite the significant change in shark swimming depth during chumming (Fig. 9), which could theoretically have led to a reduction in shark predatory pressure (Strong 1996, R. K. Laroche et al. unpubl.). The most likely explanation for this, and our estimation that predation rates were unaffected by chumming, is the general disinterest in the chum source which most sharks displayed (Fig. 3). During most daylight hours over the 'high season', our observations would suggest there are between 10 and 20 white sharks circling the waters around Seal Island (authors' unpubl. data), and although several of them may incline more towards remaining near the surface of the water and within proximity of the boat, the majority pay very little attention, thus maintaining predatory pressure at near constant levels. The result is that the mild effect of ecotourism, displayed in only a small subset of the shark population, likely has little effect on the remainder of the ecosystem.

\section{No boat effect assumption}

Many of the results presented in this paper rest on the assumption that white sharks respond to the attractant dispensed, and not to the presence of the boats themselves. Were the latter to have been the case, the receiver results would have been obscured by the fact that a portion of the control data actually reflected experimental conditions. However, several lines of evidence are consistent with the assumption, and the interpretation of the receiver data based on it.

The first of these comes from the visual records. If sharks were responding in a similar manner to boat presence itself, they would have been sighted during non-chumming conditions. Instead, although sharks did occasionally approach the boat unsolicited, these occurrences were rare, and were always extremely brief (unless some form of bait or decoy was deployed to catch their interest).

Further evidence in favour of the assumption comes from the manner in which sharks typically approached the boat. Over $85 \%$ of the initial sightings were of sharks approaching from directly below, and, of these initial approaches, the majority were made towards the sealshaped decoy (as opposed to the bait floating nearby; authors' unpubl. data). This suggests that sharks were initially responding, in accordance with their hypothesized hunting strategy, to the visual cues provided by the floating objects (Klimley 1994), rather than responding to the olfactory cues offered by the chum. This result is significant because it provides additional evidence against conditioning, which would have needed to occur in order for sharks to respond to boats without chum, because this response would not have developed on its own. The visual records of contact time also contradict the notion of conditioning, and these would not have been impacted by the assumption. Thus, our assumption of no boat effect is probably sound, and the receiver results interpreted appropriately.

\section{Experimental power}

Seal Island is 1 of 3 locations along the South African coast that support ecotourism operations. It is unique, however, in the amount of overt predatory activity that occurs in its waters - visible interactions occur roughly 2 orders of magnitude more frequently at Seal Island than anywhere else in South Africa (Martin et al. 2005). Consequently, the possibility exists that white sharks behave differently at Seal Island than anywhere else, and are less prone to respond to ecotourism offerings.

Another weakness in our results is that they are limited to the impact of a sole ecotourism operation, given that the data presented here were collected when we were the only boat chumming. However, 3 operators are granted permits to attract sharks at Seal Island, while another location on the South African coast supports 8 operations (Dyer Island, Gansbaai; R. Johnson pers. comm.). This raises the possibility that the amount of chum used in our study simply was not strong enough to elicit the changes in shark behaviour that can occur through current ecotourism activities.

Consequently, the results of the present study must be viewed cautiously, and apply predominantly to the context of low ecotourism activity at Seal Island. However, emerging data from the other ecotourism locations resemble the results presented here (R. Johnson pers. comm.), suggesting that moderate levels of ecotourism activity do not have a significant impact on white shark behaviour. Regardless, the present study has provided evidence that, although white sharks do respond to attractant (if they did not, ecotourism operations would not be viable), they are equally able to ignore the stimulus, and are thus not the mindless eating machines they are so often portrayed to be. Our results also bring into question whether other ecotourism operations, invasive or otherwise, have significant impacts on their target species. Our expectation was that tour boats would substantially affect shark behaviour, because this was their ultimate goal, and yet this did not appear to be the result. Further research is required, with this species and with others, to determine whether the results of the present study were an isolated case, or whether moderate levels of ecotourism are ubiquitously benign. 
Acknowledgements. We thank M. Meyer, S. Swanson, D. Koetze and L. Staverees of South African Marine and Coastal Management, whose tireless efforts on our behalf were instrumental in the completion of this study. The Institute for Maritime Technology provided time and resources, in the form of equipment and manpower, which proved invaluable. We also thank Vemco Inc., D. Webber, G. Coady, and R. O'Dor in particular, for the loan of acoustic equipment and for being on the other end of the phone. The South African Navy provided free harbor for our boat. Thanks to T. Campbell, C. Clarke, and to the Save Our Seas Foundation for funding, as well as to W. and K. Geisinger for making dreams come true. Thanks to D. Hunniford for assistance in the field, and to R. Johnson and N. Hammerschlag for supplementary information. Many thanks to members of SFU's Dill lab, to B. Gurd for sound statistical advice, and to R. Ydenberg, A. Harestad, C. Griffiths, and L. Compagno. Finally, R. and S. Laroche, L. and G. Kock, T. Serve and P. Menge made it all possible.

\section{LITERATURE CITED}

Abrams PA, Menge BA, Mittelbach GG, Spiller DA, Yodzis P (1996) The role of indirect effects in food webs. In: Polis GA, Winemiller KO (eds) Food webs: integration of patterns and dynamics. Chapman \& Hall, New York, p 371-395

Anderson SD, Henderson RP, Pyle P, Ainley DG (1996) White shark reactions to unbaited decoys. In: Klimley AP, Ainley DG (eds) Great white sharks: the biology of Carcharodon carcharias. Academic Press, San Diego, CA, p 223-228

Barkin D (2003) Alleviating poverty through ecotourism: promises and reality in the Monarch butterfly reserve of Mexico. Environ Dev Sustain 5:371-382

Burger J, Gochfeld M (1998) Effects of ecotourists on bird behaviour at Loxahatchee National Wildlife Refuge, Florida. Environ Conserv 25:13-21

Burgess GH (1998) Diving with elasmobranchs: a call for restraint. Shark News 11:1-3

Butterworth DS, David JHM, McQuaid LH, Xulu SS (1987) Modeling the population dynamics of the South African fur seal Arctocephalus pusillus pusillus. NOAA Tech Rep NMFS:141-164 (NTIS no.: PB88-115423)

Dill LM, Heithaus MR, Walters C (2003) Behaviorally-mediated indirect interactions in marine communities and their conservation implications. Ecology 84:1151-1157

Ferreira C, Ferreira T (1996) Observations on white sharks along the South African coast. In: Klimley AP, Ainley DG (eds) Great white sharks: the biology of Carcharodon carcharias. Academic Press, San Diego, CA, p 375-384

Frid A, Dill LM (2002) Human-caused disturbance stimuli as a form of predation risk. Conserv Ecol, available at: www.consecol.org/Journal/vol6/iss1/art11/manuscript.html

Gill JA, Sutherland WJ (eds) (2000) Predicting the consequences of human disturbance from behavioural decisions. Cambridge University Press, Cambridge

Editorial responsibility: John Roff (Contributing Editor), Wolfville, Nova Scotia, Canada
Jones S (2005) Community-based ecotourism - the significance of social capital. AnnTourism Res 32:303-324

Kiss A (2004) Is community-based ecotourism a good use of biodiversity conservation funds? Trends Ecol Evol 19: 232-237

Klimley AP (1994) The predatory behavior of the white shark. Am Sci 82:113-122

Kock AA (2002) Predatory activity of great white sharks (Carcharodon carcharias) around a Cape fur seal colony. Honour's thesis, University of Cape Town - Percy Fitzpatrick Institute

Krueger O (2005) The role of ecotourism in conservation: panacea or Pandora's box? Biodivers Conserv 14:579-600

Mangel M, Talbot LM, Meffe GK, Agardy MT and 39 others (1996) Principles for the conservation of wild living resources. Ecol Appl 6:338-362

Martin AR, Hammerschlag N, Collier RS, Fallows C (2005) Predatory behaviour of white sharks (Carcharodon carcharias) at Seal Island, South Africa. J Mar Biol Assoc UK 85:1125-1135

McClung MR, Seddon PJ, Massaro M, Setiawan AN (2004) Nature-based tourism impacts on yellow-eyed penguins Megadyptes antipodes: does unregulated visitor access affect fledging weight and juvenile survival? Biol Conserv 119:279-285

Miller ML (1993) The rise of coastal and marine tourism. Ocean Coast Manag 20:181-199

Nevin OT, Gilbert BK (2005) Perceived risk, displacement and refuging in brown bears: positive impacts of ecotourism? Biol Conserv 121:611-622

Orams MB (1995) Towards a more desirable form of ecotourism. Tour Manag 16:3-8

Orams MB (2002) Feeding wildlife as a tourism attraction: a review of issues and impacts. Tour Manag 23:281-293

Orams MB, Hill GJE, Baglioni AJ (1996) 'Pushy' behavior in a wild dolphin feeding program at Tangalooma, Australia. Mar Mamm Sci 12:107-117

Shaughnessy PD (1987) Population size of the Cape fur seal Arctocephalus pusillus pusillus. Report No. 130, Department of Environmental Affairs, Sea Fisheries Research Institute, Cape Town

Strong WR Jr (1996) Shape discrimination and visual predatory tactics in white sharks. In: Klimley AP, Ainley DG (eds) Great white sharks: the biology of Carcharodon carcharias. Academic Press, San Diego, CA, p 229-238

Wearing S, Neill J (1999) Ecotourism: impacts, potentials and possibilities, Vol 1. Butterworth Heinemann, Oxford

Williams R, Trites AW, Bain DE (2002) Behavioural responses of killer whales (Orcinus orca) to whale-watching boats: opportunistic observations and experimental approaches. J Zool 256:255-270

Wootton JT (1993) Indirect effects and habitat use in an intertidal community: interaction chains and interaction modifications. Am Nat 141:71-89

Yodzis P (2000) Diffuse effects in food webs. Ecology 81: 261-226

Submitted: March 23, 2006; Accepted: September 26, 2006 Proofs received from author(s): April 26, 2007 